\title{
Structural Audit of Old Building and It's Strengthening : Review
}

\author{
Monis Azhar Ansari ${ }^{1}$, Prof. Shrikant Solanke ${ }^{2}$, Aashish Soni ${ }^{3}$ \\ Research Scholar Department of Civil Engineering, Nagpur, Maharashtra, India ${ }^{1}$ \\ Assistant Professor Department of Civil Engineering, G.H. Raisoni College of Engineering, Nagpur, \\ Maharashtra, India ${ }^{2}$ \\ Structural Engineer, A\&S Associates Nagpur, Maharashtra, India ${ }^{3}$
}

\begin{abstract}
We are building the structures rapidly in the area where there is requirement of the structures. Every structure has its own service life. Every structure is designed by assuming its life of existence. Some of the structures gets more life than expected and some gets fail in achieving its life. Any technology or material has its limitation to withstand. Many of the structures of R.C.C. are located in Seismic prone area. The structures gets damaged due to earthquake and the structures which becomes old should be checked that whether it has the strength of existence or not. The structures should be audited timely for the safety of the human life as well as for the nearby structures. The structures can be checked by various methods of Non-Destructive Test (Rebound Hammer Test, Ultrasonic Pulse Velocity Method, Pulse Echo Method, Probe Penetration Test, Destructive Test. Rebound Hammer Test of Non-Destructive Test is used in this paper to check the strength of an institutional building. When examining the structure, this paper aims to expand the life of structure. Different techniques of Retrofitting is given to the structural member which is unsafe. By applying the retrofitting, the structure can be made safe.
\end{abstract}

Keywords : R.C.C, Structure, Rebound Hammer.

\section{INTRODUCTION}

As the spell passes strength of material will be compact due to corrosion, carbonation, alkali acid attack, earthquake, and different environmental condition. The structure can be declined due to countless reason alike superiority of concrete elements, poor workmanship, poor maintenance, structural design problems, and various loading acting on the structure. For structural strength improvement, it is essential to get an idea about the distress. According to this reasons and amount of deterioration most appropriate strength improvement technique will be adopted. To speechless this damages, repairing, reconstruction and retrofitting are the different ways for structural health development.

Present work is focused on reconstruction of RCC frame building. For finding current condition of the concrete and recent strength of concrete Non Destructive test is conducted. As par the results of NDT testing and visual inspection of building appropriate rehabilitation method will be adopted for the various deterioration of the building. 


\section{LITRETURE SURVEY}

- Nikhil R. Jagtap [1] over that strengthening and improvement of performance of existing structure in order that structure will perform well once subjected to extra hundreds over it. The current work deals with NDT on existing structural component/determination of load moment carrying capability of structural elements before and extension, methodology applied for strengthening of structure, design of present structural components like R.C.C beams and columns per the load carrying capability needed.

- Patil S.R. Prof. Sayyed G.A [2] In terms of two restoration of extensive damages in R.C.C micro concrete: small concrete could be a terribly high strength combine style concrete, its factory made product. Its dry powder in grey colour more like cement constitutes cement as a one component \& other's graded fine aggregate, additive in powder form \& free flowing agent, because of this small concrete will placed in less thickness. Material can travel in narrow gape \& having self-levelling properties, so that it provides very smooth \& uniform finish. Civil engineering industry is one of the oldest industries which provide a basic infrastructure to all the human beings.

Civil Engineering Industry is one of the oldest industries which provide a basic infrastructure to all the human beings. Structure is any kind it is Historical, Heritage structure, Residential building, Commercial building or an industrial building. Every structure has its own service life, and within this service life it should stand firmly on its position. Ex-Taj Mahal in Agra in India which is one of the oldest structure and a wonders of the world, and still stands on its position very efficiently. But this not a condition about the today's structure. A collapsed mechanism has and today's structure have gotten folded before there service life is completed. Structural audit could be a preliminary technical survey of a building to assess its general health as a engineering science structure, It is sometimes initiated because the start of repair. In this project a Root reason behind a faulty mechanism of structure and a preventive measure to beat a failure of this structure.

- M.M. Sonawane, D.H. Markad, V.G. Maindad, M.B. Patil, K.D. Manwar, P.D. Mote [3] Decided that suitable activities should then be effected to recover the performance of structures and restore the desired function of structures. Thus, it is almost important to perform structural audit of existing buildings and to implement carrying / renovation work time which will lead to prolonged life of the construction and safety of the occupant.

- Pranjali V Kulkarni, etal [4] They studied various cases related to old RCC structures and reviewed the auditing process referring various problems related to auditing process. Currently, Safety of old buildings is single of the lifethreatening matters in India. Though, there are many practices to conduct structural audit of such buildıngs, the issues of structural safety audit remains uncertain due to inconsistency of such practices. The study attempts to evaluate gaps in current such local practices of structural audit of residential building's. There by intends to offer insights to produce additional precise framework of structural audit. The flaws in the process of structural audit and the difficulties in execution of structural audit were studied. Also the recommendations for the safe and universally acceptable framework to carry out structural audit were also studied. 
- BH Chafekar, etal [5] To carryout structural audit we must know various details about the structure. This helps in proper evaluating various causes of distress its causes and weak areas in the structure by referring the RCC building as an interconnected structure made of elements to carry load safely to the underground earth by considering the example of table as structure. The legs of tables are column, battens are the beam and ply sheet are slab. When they are joined vertically and horizontally a structure is formed in the similar technique the construction building is selfpossessed of steel and concrete. However after its long use the table drops its load carrying capacity similarly RCC structures also loses its strength due to material deterioration and when it becomes old. Hence it becomes mandatory to take some actions to overcome this problem. The health examination of the concrete building is called a structural audit. Which consist of a full review of the building like a doctor. For old building proven to risk areas, critical areas and weak structural areas etc structural audit becomes a necessary tool to regain overall health of the structure by suggesting various repair techniques wherever necessary.

- J.C Agunwala, etal [6] Done a comparative study of NDT Techniques including rebound hammer test \& Ultrasonic Pulse velocity test. Advised that NDT of concrete is of great scientific and practical importance especially for defining class of old Concrete Test was perform to relate the accuracy $\mathrm{b} / \mathrm{w}$ Rebound hammer and UPV method with two different properties in estimating the strength concrete. The sample were prepared and tested and the comparison strength was calculated.
- J.Bhattacharjee [7] Studied present status of maintenance repair and rehabilitation techniques in India and found that India lacks various advanced methods of rehabilitation and retrofitting techniques. At present there is neither any established procedure mandatory to carry out the auditing process. Also studied various causes of distress and cracks in the structure, various measures to be adopted to restore the strength of the structure. The study also includes various major causes of deterioration of the structures. He also studied various case studies related to structural auditing which includes repair and rehabilitation of jetty at Mumbai, rehabilitation of an overhead reservoir at Siliguri. West Bengal Double storied load bearing structure in Mumbai. Also studied various precautions to be taken while using chemicals for repairs.

- Amritha and Anju Paul [8] decided that the analysis and designing of standing old structure which was essentially designed for seismic zone II as per the previous code i.e. IS 1893: 1984 and remodelling the structure according to the revised code i.e. IS 1893: 2002 for seismic zone III. Pillars are initiate to be the lacking member and are to be retrofitted so as to succeed yielding performance. The utmost proper retrofitting procedure i.e. usage of FRP wrapping is recommended for the retrofitting of the lacking columns.

\section{III.CONCLUSION}

From the N.D.T. Rebound Hammer test report, it is concluded that the structure is within safe limits and retrofitting is provided with the different suggestions to the members which are not safe and which are damaged. The report is based only on NDT, visual inspection of the assessable area and the data provided 
by the client. In the time off of design data and structural drawings, the resistance to seismic forces cannot be assessed. Overall the Structure is safe to meet its current functional requirement.

\section{REFERENCES}

[1]. Nikhil L.Jagtap, Prof. P. R. Mehetre "Study on Retrofitted R.C.C. Building by Different NDT Methods" IOSR Journal of Mechanical and Civil Engineering (IOSR-JMCE) (May - Jun 2015)

[2]. Patil S.R., Prof. Sayyed G.A "STRUCTURAL AUDIT" IOSR Journal of Mechanical an Civil Engineering (IOSR-JMCE) e-ISSN : 2278-1684, p-ISSN : 2320-334X PP 60-64.

[3]. Building and Construction Authority, "Periodic Structural Inspection of Existing Buildings", January 2012Central PWD, "Handbook on repair and rehabilitation of RCC Buildings", July 2010

[4]. Pranjali V. Kulkarni, Sachin V. Admane, "Simplifying and Managing the process of Structural Audit", Engineering and scientific International Journal (ESLJ), Volume 2, Issue 1, January, March 2015.

[5]. BH Chafekar, O.S Kadam, K.B Kale, S.R Mohite, P.A Shinde, V,O Koyle, "Structural Audit" International Journal of Civil And Structural Engineering Research (IJCSER) Vol. 1, Issue 1, pp:(42-46), Month: October 2013-March 2014.

[6]. J.C. Agunwamba, T. Adegba "A Comparative Analysis of The Rebound Hammer And Ultrasonic Pulse Velocity In Testing Concrete", Nigerian Journal of technology (NIJOTECH) Vol. 31, No. 1, March, 2012, pp. 31-39.

[7]. J Bhattacharjee, "Repair Rehabilitation and Retrofitting of RCC for Sustainable Development with Case Studies" Civil Engineering and Urban Planning an International Journal Vol. No. 2 June 2016.
[8]. Amritha Rangandhan, Anju Paul "SEISMIC RETROFITTING OF AN EXISTING STRUCTURE" IJRTE: International Journal of Research in Engineering and Technology eISSN: 2319-1163 pISSN: 2321-7308

[9]. Krish R. Villaitramani” PREFABRICATED CONSTRUCTION FOR MASS HOUSING IN MUMBAI" International Journal of Innovative Research in Advanced Engineering (IJIRAE) ISSN: 2349-2163 Volume 1 Issue 9 (October 2014).

[10]. Indian standard: 516: 1959- Method of test for strength of concrete.

[11]. Indian standard: 13311: 1959- (Part 2) NDT methods of Test-Rebound Hammer.

[12]. Indian standard: 13311: 1959- (Part 1) NDT methods of Test-U.P.V

\section{Cite this article as :}

Monis Azhar Ansari, Prof. Shrikant Solanke, Aashish Soni, "Structural Audit of Old Building And It's Strengthening : Review ", International Journal of Scientific Research in Science and Technology (IJSRST), Online ISSN : 2395-602X, Print ISSN : 23956011, Volume 7 Issue 2, pp. 563-566, March-April 2020. Available at doi : https://doi.org/10.32628/IJSRST2072104 Journal URL : http://ijsrst.com/IJSRST2072104 